\title{
ERRATUM
}

\section{Referring strategies in American Sign Language and English (with co-speech gesture): The role of modality in referring to non-nameable objects-ERRATUM}

\author{
ZED SEVCIKOVA SEHYR \\ San Diego State University \\ BRENDA NICODEMUS \\ Gallaudet University
}

JENNIFER PETRICH and KAREN EMMOREY

San Diego State University

doi: 10.1017/S0142716418000061, published by Cambridge University Press, 17 April 2018

In the article by Sehyr et al., the acknowledgments section was omitted from the final published article due to an error made during the copyediting process. The complete acknowledgments section is provided below.

\section{ACKNOWLEDGMENTS}

We would like to thank Cindy O'Grady Farnady, Nicole Denny, Christiana David, and Elisabeth Lottman for assistance with this project. The research was supported by the National Institutes of Health (grant no. DC010997) to K.E.

\section{REFERENCE}

Sehyr, ZS., Nicodemus, B., Petrich, J., \& Emmorey, K. (2018). Referring strategies in American Sign Language and English (with co-speech gesture): The role of modality in referring to non-nameable objects. Applied Psycholinguistics, 39, 961-987. 